\title{
Relationships of diversity, disparity, and their evolutionary rates in squirrels (Sciuridae)
}

\author{
Miriam L. Zelditch, ${ }^{1,2}$ Jingchun Li, ${ }^{3,4}$ Lucy A. P. Tran, ${ }^{4}$ and Donald L. Swiderski ${ }^{3,5}$ \\ ${ }^{1}$ Museum of Paleontology, University of Michigan, Ann Arbor, Michigan 48109 \\ 2E-mail: zelditch@umich.edu \\ ${ }^{3}$ Museum of Zoology, University of Michigan, Ann Arbor, Michigan 48109 \\ ${ }^{4}$ Department of Ecology and Evolutionary Biology, University of Michigan, Ann Arbor, Michigan 48109 \\ ${ }^{5}$ Kresge Hearing Research Institute, University of Michigan, Ann Arbor, Michigan 48109
}

Received September 14, 2014

Accepted March 9, 2015

\begin{abstract}
Several theories predict that rapidly diversifying clades will also rapidly diverge phenotypically; yet, there are also reasons for suspecting that diversification and divergence might not be correlated. In the widely distributed squirrel clade (Sciuridae), we test for correlations between per lineage speciation rates, species richness, disparity, and a time-invariant measure of disparity that allows for comparing rates when evolutionary modes differ, as they do in squirrels. We find that species richness and speciation rates are not correlated with clade age or with each other. Disparity appears to be positively correlated with clade age because young, rapidly diversifying Nearctic grassland clades are strongly pulled to a single stable optimum but older, slowly diversifying Paleotropical forest clades contain lineages that diverge along multiple ecological and morphological lines. That contrast is likely due to both the environments they inhabit and their phylogenetic community structure. Our results argue against a shared explanation for diversity and disparity in favor of geographically mediated modes of speciation and ecologically mediated modes of phenotypic evolution.
\end{abstract}

KEY WORDS: Adaptive radiation, macroevolution, morphology, Rodentia, shape, size.

Some clades are notable for both their diversity and disparity, and others are remarkable for their lack of both. Examples of such contrasts abound in mammals, such as that between Rodentia, an order comprising more than 2200 species including woodchucks, porcupines, beavers, deer mice, roof rats, and flying squirrels, and the eight species of scaly anteaters (pangolins) in the order Pholidota or the single species of aardvark constituting Tubulidentata (Wilson and Reeder 2005). Such striking contrasts suggest that diversification and morphological evolution are related to each other, and several hypotheses do link them indirectly or directly. One hypothesized indirect link is clade ageboth diversity and disparity take time to accumulate, hence older clades will be more diverse and more disparate than younger ones (O’Meara 2006; McPeek and Brown 2007; Wiens et al. 2011). A more direct link is ecological opportunity that, according to an influential model for adaptive radiations, promotes both diversification and adaptive divergence (Simpson 1953; Walker and Valentine 1984; Schluter 1996; Mahler et al. 2010; Yoder et al. 2010). In an alternative ecological hypothesis, high diversification rates are expected in clades whose necessary resources disappear during recurrent environmental extremes because these clades should have a high incidence of strong directional selection and vicariance (hence speciation) (Vrba 1987). Still other models posit an even more direct causal relationship between diversification and divergence, making one dependent on the other. According to one such hypothesis, divergence is a function of the number of speciation events; species-rich clades are expected to be more disparate than species-poor ones (Pagel 1997; Ricklefs 2004; Mattila and Bokma 2008). Other hypotheses reverse the direction of causality, proposing that some clades have an 
intrinsically greater capacity to evolve novel morphologies (Lovette et al. 2002). Such clades may therefore exploit a wider variety of niches, which would weaken ecological controls on species richness and lead to a higher rate of diversification (Rabosky 2012; Rabosky et al. 2013).

There are at least as many reasons for anticipating no correlation between diversity and disparity as for anticipating a positive one. First, the dependence of diversity and disparity on time is weakened by variation in rates among clades because diversity and disparity are then dependent on the variation in rate and not just age. Second, that dependence is weakened by temporal changes in rates, such as diversity-dependent decelerations in speciation rates (Alfaro et al, 2009b; Etienne and Haegeman 2012; Rabosky et al. 2012) or adaptation to a stable adaptive peak (Hansen and Martins 1996; Hansen 1997). Third, the circumstances required to link diversification to divergence ecologically might not be general enough to yield a regular relationship between diversity and disparity. For example, ecological opportunity does not always lead to a classic early burst of both diversification and divergence (Burbrink et al. 2012b), even when clades share the same sources of ecological opportunity (Burbrink et al. 2012a). Also, key innovations that confer ecological opportunity need not increase diversification rates (Claramunt et al. 2012), even when disparity is elevated (Alfaro et al. 2009a; Dornburg et al. 2011), and may even depress diversification (Tran 2014). Fourth, a link between diversification and divergence is not expected for some kinds of radiations, especially those termed "nonadaptive," in which diversification is not accompanied by niche divergence (Gittenberger 1991; Wilke et al. 2010); consequently, nonadaptively radiating clades are diverse but not disparate (e.g., Kozak et al. 2006; Rowe et al. 2011; Smith et al. 2011). Finally, iteratively radiating clades may decouple diversification and divergence by converging toward similar sets of habitats (Cooper and Westneat 2009; Frederich et al. 2013; Mahler et al. 2013).

Despite several reasons for expecting no general relationship between diversification and morphological divergence, two recent studies that explicitly tested for a correlation between per lineage diversification and morphological divergence rates found them to be correlated (Rabosky and Adams 2012; Rabosky et al. 2013). In one, the correlation is between speciation rates and divergence rates (Rabosky et al. 2013); in the other, it is between species richness and divergence rates (Rabosky and Adams 2012). The distinction between using diversification rate versus species richness as the measure of diversification is important because the primary advantage of using a rate is that it is time-invariant, that is, the process depends on time but its rate does not vary with time. But that is true only if the rate is constant. If the model underlying the estimation of a rate is linear and rates are not constant, the estimated diversification rate is not time-invariant. In the case of diversity-dependent speciation, species richness is
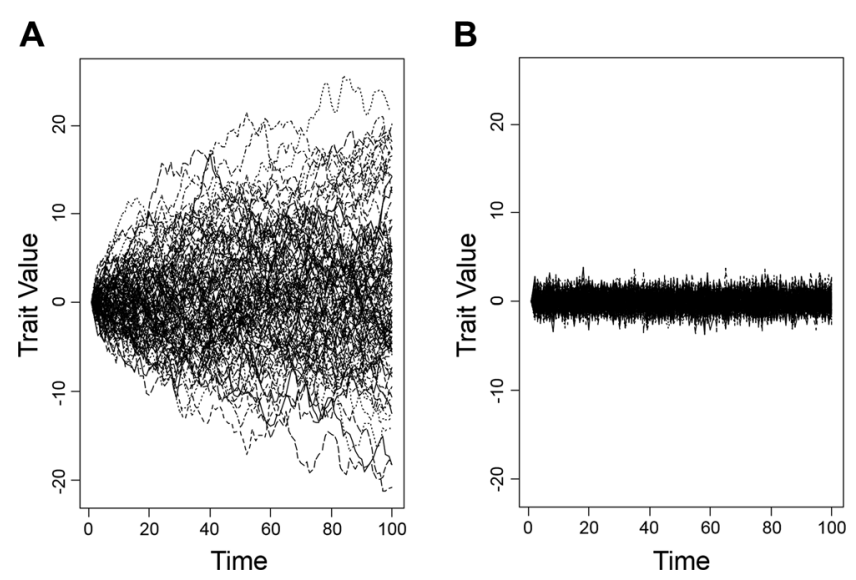

Figure 1. Temporal patterns of disparity for clades with the same $\sigma^{2}$ and different $\alpha$. (A) Low $\alpha$, (B) high $\alpha$.

a better measure of diversification (Rabosky and Adams 2012). The same considerations apply to measuring rates of phenotypic divergence. When they are modeled as constant using a model of Brownian motion, but phenotypes instead evolve toward a stable optimum, the estimated rates are not time-invariant. The metric for estimating the tempo of evolution depends on a model, making tempo and mode inseparable (Hunt 2012). This inseparability of tempo and mode poses a serious problem for estimating per lineage rates of phenotypic divergence when clades exhibit different modes of phenotypic evolution. Under those conditions, rate metrics are not comparable across clades because they are not comparable across modes. The most commonly used model measures evolutionary rate by the Brownian rate parameter $\sigma^{2}$; but when phenotypes evolve toward a stationary optimum, the rate of divergence decreases with decreasing distance from the optimum and disparity is determined by a balance between the strength of attraction to the stationary peak $(\alpha)$ and the (short-term) Brownian rate parameter $\left(\sigma^{2}\right)$ (Martins 1994; Hansen and Martins 1996). Clades that have the same value for $\sigma^{2}$ but different values for $\alpha$ differ strikingly in their temporal patterns of disparity (Fig. 1). Because there is no simple, general metric for an evolutionary rate, there is no straightforward method for measuring per lineage rates across lineages that differ in mode.

Differences in evolutionary mode might be common in clades that proliferate over multiple continents, through several geological intervals and within different ecological settings. Herein, we focus on one such lineage, the squirrels (Sciuridae). There are approximately 285 living species (Thorington et al. 2012) distributed over all continents save Australia and Antarctica. The lineage originated in the late Eocene of North America, approximately 36 million years ago (Ma) (Emry and Thorington 1982; Emry and Korth 2007). Differences in evolutionary mode are anticipated because the genus encompassing most Nearctic tree squirrels (Sciurus) has been characterized as a living fossil 
(Emry and Thorington 1984), whereas the sister group of that clade, the flying squirrels (Pteromyini), has been interpreted as an adaptive radiation (Thorington et al. 2002). Moreover, differences in diversification rate in Sciuridae have been documented (Fabre et al. 2012). Perhaps most importantly, Paleotropical communities contain lineages giving rise to arboreal, semiarboreal, and terrestrial squirrels and multiple trophic and locomotory ecomorphs, whereas Nearctic communities contain distantly related groups (tree squirrels [Sciurini], semiarboreal squirrels [Tamias], and ground squirrels [Marmotina]).

In this analysis of diversity and disparity, we largely follow the methods used in the pioneering studies by Adams et al. (2009), Rabosky and Adams (2012), and Rabosky et al. (2013), modified for lineages that differ in evolutionary mode. We focus on two morphological traits, body size and jaw shape. Size is the most widely studied trait in studies of adaptive radiations, and it is of particular interest in squirrels because they have undergone multiple instances of dwarfing and gigantism, which are typically associated with trophic specialization. Size is also one of the lines along which coexisting, ecologically similar species diverge (MacKinnon 1978; Emmons 1980; Payne 1980). Trophic ecology is another main line of divergence, and jaw shape is likely to be closely tied to diet. We first present a new phylogenetic analysis of Sciuridae, then test for changes in speciation rate in the lineage as a whole. We then divide the lineage into a set of mutually exclusive clades and test for correlations among speciation rate, species richness, disparity, and a time-invariant measure of disparity, an alternative to measuring rates across lineages that differ in evolutionary mode suggested by Hunt (2012, p. 369).

\section{Methods}

Unless otherwise noted, all analyses were performed in R 3.0 or later (R Core Team 2014); specific functions or packages are cited in context, below.

\section{PHYLOGENY RECONSTRUCTION}

Gene sequence data were obtained for five mitochondrial genes (16S, 12S, COII, COIII, and Cyt-b) and three nuclear genes (C-myc, IRBP, and RAG1) representing 189 species from 57 of 58 genera and accounting for $66 \%$ of the known extant species in Sciuridae (Supporting Information). Outgroups were the protogomorph, Aplodontia rufa, and three glirids (Glis glis, Graphiurus murinus, and Muscardinus avellanarius). The majority of the sequences were from the original alignments of a recent rodent phylogeny (Fabre et al. 2012). Several sequences associated with questionable taxonomical identifications in Genbank were replaced by sequences from reliably identified voucher specimens (Supporting Information). Additional sequences for species in Tamias and Marmota were obtained based on Piaggio and Spicer (2000) and Steppan et al. (2011).
All sequences were aligned using MUSCLE (Edgar 2004) implemented in CodonCode Aligner 3.1.7 and corrected by eye. Substitution models were selected using PartitionFinder (Lanfear et al. 2012) based on Bayesian information criterion. The $\mathrm{SYM}+\mathrm{I}+\mathrm{G}$ substitution model was selected for C-myc, COII, COIII, and Cyt-b; the GTR+I+G model was selected for the other genes.

The tree topology and divergence times were estimated simultaneously in BEAST 1.7.3 (Drummond et al. 2012). The substitution model for each gene was based on the PartitionFinder results, except that the proportion of invariant sites was not applied as it may add unnecessary model complexity (Allman et al. 2008). A relaxed molecular clock with an uncorrelated lognormal distribution was used and partitioned by genes (all mitochondrial genes were considered as one partition). A Yule process was used for the speciation model. Three calibration points were based on fossil occurrences and tectonic events, following Mercer and Roth (2003). Minimal age offsets were set as follows: Sciuridae, $36 \mathrm{Ma}$; Sciurini (Sciurus, Microsciurus, Syntheosciurus, and Rheithrosciurus), $10 \mathrm{Ma}$; and Atlantoxerus getulus, $14 \mathrm{Ma}$. Lognormal priors with mean $=1$ and $\mathrm{SD}=1$ were applied to all calibration points. Two independent Markov chain Monte Carlo (MCMC) analyses were run on the Cipres Gateway (http://www.phylo.org); each was run for 100 million iterations and sampled every 1000 iterations. MCMC performance was examined using Tracer version 1.5 (http://beast.bio.ed.ac.uk/Trace) to ensure the two chains converged and reliable effective sampling sizes (>200) were reached. Posterior trees from the two runs were combined after burnin $(20 \%$ for run 1 and $40 \%$ for run2) and "thinned" to 10,000 trees in LogCombiner (http://beast.bio.ed.ac.uk/LogCombiner). A maximum credibility consensus tree was generated from the 10,000 trees in TreeAnnotater (http://beast.bio.ed.ac.uk/TreeAnnotator) and was used for all further analyses.

\section{DIVERSIFICATION RATE}

Lineage diversification rates and rate shifts were inferred from reversible jump MCMC (rj-MCMC) analyses, implemented in BAMM (Rabosky 2014). These analyses were performed on the consensus tree inferred by our phylogenetic analyses. All recognized extant species were included in this analysis; those species that were not included in the phylogenetic analysis were assigned to the smallest possible clade based on prior taxonomic and biogeographic studies (Supporting Information). Two independent runs $\left(1 \times 10^{7}\right.$ and $3 \times 10^{7}$ generations, sampled every $10^{4}$ generations) were evaluated for MCMC convergence and high effective sample size ( $>200$ ), using functions in the R package coda (Plummer et al. 2006). We confirmed that the runs converged on the same number and positions of rate shifts, with equivalent Bayes factors for the difference between prior and posterior probabilities of those shifts, using BAMMtools (Rabosky 
Table 1. Clades used in tests of evolutionary rate correlations.

\begin{tabular}{|c|c|c|c|c|}
\hline Clade name & Genera & $\begin{array}{l}\text { Crown } \\
\text { age }(\mathrm{Ma})\end{array}$ & $\begin{array}{l}\text { Number of } \\
\text { named species }\end{array}$ & $\begin{array}{l}\text { Number of } \\
\text { species included }\end{array}$ \\
\hline "Cynomys" & $\begin{array}{l}\text { Cynomys, Ictidomys, } \\
\text { Poliocitellus, } \\
\text { Xerospermophilus }\end{array}$ & 7.9 & 13 & 12 \\
\hline Urocitellus & Urocitellus & 6.2 & 12 & 10 \\
\hline Spermophilus & Spermophilus & 8.2 & 15 & 12 \\
\hline Marmota & Marmota & 5.8 & 15 & 14 \\
\hline "Otospermophilus" & $\begin{array}{r}\text { Callospermophilus, } \\
\text { Otospermophilus }\end{array}$ & 8.9 & 6 & 6 \\
\hline “Ammospermophilus" & $\begin{array}{l}\text { Ammospermophilus, } \\
\text { Notocitellus }\end{array}$ & 13.6 & 5 & 4 \\
\hline Tamias & Tamias & 14.3 & 25 & 25 \\
\hline Protoxerini & $\begin{array}{l}\text { Epixerus, Funisciurus, } \\
\text { Heliosciurus, Myosciurus, } \\
\text { Paraxerus, Protoxerus }\end{array}$ & 20.6 & 31 & 15 \\
\hline Xerini & $\begin{array}{l}\text { Atlantoxerus, Spermophilopsis, } \\
\quad \text { Xerus }\end{array}$ & 24.5 & 6 & 6 \\
\hline Sciurini & $\begin{array}{l}\text { Microsciurus, Rheithrosciurus, } \\
\text { Sciurus, Syntheosciurus, } \\
\text { Tamiasciurus }\end{array}$ & 17.3 & 37 & 28 \\
\hline "Glaucomys" & $\begin{array}{l}\text { Eoglaucomys, Glaucomys, } \\
\text { Hylopetes, Iomys, } \\
\text { Petaurillus, Petinomys }\end{array}$ & 15.9 & 25 & 11 \\
\hline "Pteromys" & $\begin{array}{c}\text { Aeretes, Aeromys, Belomys, } \\
\text { Eupetaurus, Pteromys, } \\
\text { Pteromyscus, Trogopterus }\end{array}$ & 16.3 & 9 & 8 \\
\hline Petaurista & Petaurista & 11.0 & 9 & 6 \\
\hline "Sundasciurus" & $\begin{array}{l}\text { Menetes, Nannosciurus, } \\
\text { Prosciurillus, Rhinosciurus, } \\
\text { Rubrisciurus, Sundasciurus }\end{array}$ & 14.3 & 28 & 20 \\
\hline "Callosciurus" & $\begin{array}{c}\text { Callosciurus, Glyphotes, } \\
\text { Hyosciurus, Lariscus }\end{array}$ & 11.8 & 21 & 8 \\
\hline "Dremomys" & Dremomys, Tamiops & 12.8 & 10 & 7 \\
\hline "Ratufa" & Ratufa, Sciurillus & 32.7 & 6 & 4 \\
\hline
\end{tabular}

Clades were delineated using our phylogenetic result (Fig. S1). Clades that encompass multiple genera but do not have formal taxonomic names are named for an included genus and are given in quotation marks and roman font (cf., "Cynomys" vs. Urocitellus).

et al. 2014). BAMM tests models of speciation and extinction, as well as the net diversification rate, but because our data include only extant taxa, we analyze only the variation in speciation rate.

To test for correlations between speciation rate and other clade attributes, we first divided the family into several mutually exclusive (non-nested) monophyletic groups based on our phylogenetic analysis. Only clades supported by posterior probabilities $\geq 0.8$ were used. To avoid problems arising from small sample sizes, all included clades are represented by at least four species (usually $>9$ ) in both the molecular and morphological datasets (Supporting Information). To increase statistical power of these analyses, we also maximized the number of clades by excluding basal genera represented in the phylogenetic analysis by $<4$ species in asymmetric and highly speciose clades (Sciurotamias in Marmotini; Exilisciurus and Funambulus in Callosciurinae). This allowed us to subdivide those clades and yielded 17 focal clades for testing correlations of speciation rate with species richness, clade age, and rates of size and shape evolution (Table 1). Many of these 17 clades include multiple genera, but do not have formal taxonomic names; these are indicated using the name of an included genus that is given in quotation marks and roman font (i.e., "Cynomys" not Cynomys). Estimates of crown ages for all 17 focal clades are based on the consensus tree for the full dataset. Species richness values represent all recognized extant species of the focal clades. Average speciation rate for each 


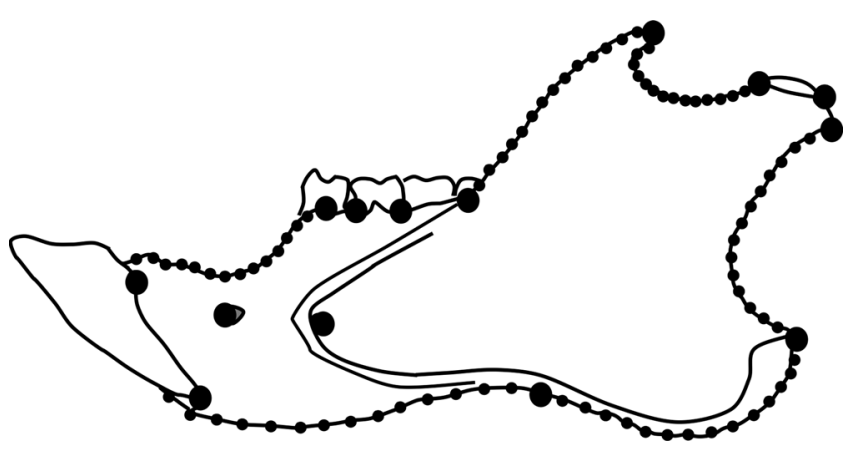

Figure 2. Landmarks (large circles) and semilandmarks (small circles) on a representative Sciurus niger mandible.

clade was extracted from the complete rate model fit to the entire tree by using the getCladeRates function in BAMMtools.

\section{MORPHOLOGICAL DATA}

To sample trophic morphology, we quantified mandibular shape and size, sampling 14 landmarks on photographs of mandibles taken in lateral view (Fig. 2). Because these landmarks do not effectively capture the complex curvature of the jaw, we also sampled 84 semilandmarks. Landmarks and semilandmarks were digitized in tpsDig 2.16 (Rohlf 2010). We measured 1677 adults from 185 species; sample sizes range from 1 to 31, with a mean of 9 (sampled species are indicated in Supporting Information). The only genera not represented are the monotypic Eupetaurus, Biswamoyopterus (two species of flying squirrel, each known from a single specimen), and Hyosciurus. Of the 185 species, 168 are also in the phylogenetic analysis; the other 17 are used to estimate the impact of incomplete sampling on estimates of disparity. Nine of the 17 are from a notably undersampled group, New World Sciurini; four are from another undersampled group, Protoxerini; three are from Callosciurinae; and one is from Spermophilus.

Landmarks were superimposed by Generalized Procrustes analysis (GPA), sliding semilandmarks to minimize bending energy (Green 1996; Bookstein 1997; Zelditch et al. 2012). Size was measured as the centroid size of the jaw (ln-transformed, LCS). This is a measure of mandibular size, but it is highly correlated with overall body size; to estimate that correlation, we used values for mass of the 138 species tabulated by Hayssen (2008) that also are present in our dataset; the correlation between ln-transformed cube root of mass and LCS is 0.97. Following superimposition, mean shape and mean size were computed for each species. GPA was done in the geomorph package (Adams and Otarola-Castillo 2013). To measure shape disparity we used the Procrustes variance, which is the average Procrustes distance of each species' shape to its clade's mean shape, and is equivalent to the sum of variances over all superimposed coordinates (Klingenberg and McIntyre 1998; Zelditch et al. 2003). For size disparity, we used the variance of LCS. Phylogenetic distributions of size and shape were illustrated using plotGMPhyloMorphoSpace in geomorph (for shape) and traitgram in picante (for size), (Kembel et al. 2010); as a measure of phylogenetic signal, we use the multivariate version of Blomberg's K statistic, using the physignal function in geomorph.

\section{MEASURING PHENOTYPIC DIVERGENCE}

To determine whether we could use the Brownian rate parameter to measure divergence rates, we used two methods, both equally suitable to univariate and high-dimensional data: (1) the node-height test (Freckleton and Harvey 2006) and (2) the morphological disparity index (MDI) (Harmon et al. 2003). The node-height test uses standardized phylogenetic independent contrasts, comparing those with expectations under a Brownian motion model, which predicts that those contrasts do not covary with node height. To apply this test to shape data, we used a multivariate procedure for estimating contrasts, which are the square root of sums of squared univariate contrasts (McPeek et al. 2008). Univariate standardized independent contrasts were calculated using the pic function in ape (Paradis et al. 2004). For size, we used the nh.test function in geiger (Harmon et al. 2008). The MDI statistic measures the deviation from expectations for relative within-clade disparities under a model of Brownian motion. MDI is calculated as the area between the line connecting observed relative disparities to that connecting median relative disparities simulated under a Brownian model; the area above the median is the positive deviation, that below is the negative. To determine if MDI differs significantly from zero, MDI is calculated for 1000 datasets simulated under Brownian motion and the $P$-value is the proportion of cases in which an MDI more extreme than the observed one is obtained. Two-tailed tests for the statistical significance of the MDI were performed using the dttFullCIs function of Slater (http://fourdimensionalbiology.com/code/) (Slater et al. 2010).

\section{ESTIMATING TIME-INVARIANT DISPARITY}

Taken together, the preliminary analyses show that the data for many clades do not conform to the expectations of Brownian motion (Table 2). Even so, we cannot assume that disparity is strictly time-invariant and simply use the observed disparity instead of a time-invariant measure. Given the differences in mode, and the resultant incommensurability of rate metrics (Fig. 1), we estimated time-invariant disparity by predicting the disparity that would accrue over $36 \mathrm{Myr}$, the age of the sciurid clade. To estimate that, we used the parameters of a model describing phenotypic divergence. To determine which model to use, we fit three to the data: Brownian motion (BM), Early Burst (EB), and a single stationary peak Ornstein-Uhlenbeck (SSP). Models were fit to the size data using the fitContinuous function in geiger. Because of the high-dimensionality of shape data, we first reduced dimensionality by a principal components analysis (PCA). Ideally, we 
Table 2. Results from the node-height test and the MDI statistic, which measures the area between the median of relative disparities of data simulated under Brownian motion and the data.

\begin{tabular}{|c|c|c|c|c|c|c|c|c|}
\hline & \multicolumn{4}{|c|}{ Node-height test } & \multicolumn{4}{|l|}{ MDI } \\
\hline & \multicolumn{2}{|l|}{ Size } & \multicolumn{2}{|l|}{ Shape } & \multicolumn{2}{|l|}{ Size } & \multicolumn{2}{|l|}{ Shape } \\
\hline & Slope & $P$ & slope & $P$ & MDI & $P$ & MDI & $P$ \\
\hline "Cynomys" & 0.0084 & 0.558 & 0.0034 & 0.238 & -0.268 & 0.000 & 0.111 & 0.305 \\
\hline Urocitellus & 0.0315 & 0.020 & 0.0049 & 0.000 & 0.519 & 0.020 & 0.422 & 0.044 \\
\hline Spermophilus & -0.0039 & 0.277 & 0.0015 & 0.000 & 0.323 & 0.021 & 0.243 & 0.006 \\
\hline Marmota & 0.0082 & 0.080 & 0.0007 & 0.055 & 0.171 & 0.047 & 0.458 & 0.021 \\
\hline "Otospermophilus" & 0.0003 & 0.977 & 0.0073 & 0.018 & 0.712 & 0.000 & 0.283 & 0.334 \\
\hline "Ammospermophilus" & 0.0097 & 0.256 & 0.0024 & 0.172 & -0.206 & 0.003 & -0.060 & 0.267 \\
\hline Tamias & 0.0033 & 0.131 & 0.0034 & 0.000 & 0.129 & 0.177 & 0.270 & 0.036 \\
\hline Protoxerini & -0.0006 & 0.814 & 0.0003 & 0.647 & -0.141 & 0.024 & -0.163 & 0.002 \\
\hline Xerini & -0.0018 & 0.124 & 0.0005 & 0.334 & 0.004 & 0.526 & 0.047 & 0.404 \\
\hline Sciurini & 0.0060 & 0.232 & 0.0017 & 0.005 & 0.346 & 0.000 & 0.385 & 0.000 \\
\hline "Glaucomys" & 0.0104 & 0.037 & 0.0002 & 0.774 & -0.272 & 0.000 & 0.206 & 0.308 \\
\hline "Pteromys" & 0.0034 & 0.290 & 0.0013 & 0.108 & 0.187 & 0.140 & 0.472 & 0.225 \\
\hline Petaurista & -0.0045 & 0.307 & 0.0004 & 0.775 & -0.073 & 0.299 & -0.067 & 0.000 \\
\hline "Sundasciurus" & 0.0155 & 0.152 & 0.0090 & 0.016 & 0.174 & 0.005 & 0.041 & 0.000 \\
\hline "Callosciurus" & 0.0051 & 0.612 & 0.0018 & 0.446 & 0.612 & 0.001 & 0.620 & 0.000 \\
\hline "Dremomys" & -0.0074 & 0.119 & 0.0035 & 0.010 & 0.124 & 0.099 & 0.045 & 0.277 \\
\hline "Ratufa” & -0.0050 & 0.152 & -0.0001 & 0.870 & -0.269 & 0.001 & -0.098 & 0.007 \\
\hline
\end{tabular}

would use all PCs that have nonzero eigenvalues, but there are too many relative to the number of species so we used the set of PCs that span as close to $96 \%$ of the variance as possible. For 14 clades, the PCs span $95-98 \%$ of the variance but for three they span less (Urocitellus, 94\%, Spermophilus, 93\%, and Xerini, $91 \%)$. Models were fit to the full set of PCs as a multivariate set using the transformPhylo.ML function in motmot (Thomas and Freckleton 2012) or the function fitContinuousMV (code provided by Graham Slater). These analyses return a single value for the pull to the optimum $(\alpha)$ for an SSP model or for the rate-change parameter $(a)$ for an EB model for each set of PCs, as appropriate for multidimensional shape data. The values do depend, at least slightly, on the proportion of variance explained; for example, in the case of "Sciurini," over the range of 9-13 PCs, which account for $95.6-98.7 \%$ of the variance, the estimate for $\alpha$ ranges from 0.61 to 0.69 . We estimated the Brownian rate parameter $\left(\sigma^{2}\right)$ from the sum of the diagonals of the rate matrix, transforming the tree using estimated values of $\alpha$ or $a$; for a more thorough discussion on estimating an evolutionary rate for shape, see Adams (2014b). When the likelihood surface was flat, we fit a series of models with varying values of $\alpha$, using the function transformPhylo.ll in the motmot package to find the smallest value with maximum likelihood. We did not use an information theoretic approach to model selection because our aim was to simulate the data hence we did not penalize models having additional parameters.
Before using these estimates of $\sigma^{2}, \alpha$, and $a$ to predict timeinvariant disparity, we simulated divergence of each clade on its own tree (1000 times) using the rTraitCont function in ape and compared the mean of the simulated values to the observed one. Discrepancies between these values indicate the model does not accurately predict the observed disparity. The estimated values of $\sigma^{2}, \alpha$, and $a$ accurately predicted observed size disparity in only nine of the 17 clades. The median discrepancy was 5.1\% but in five cases, it exceeded 10\% ("Dremomys," Tamias, "Ammospermophilus," "Otospermophilus," and "Ratufa") and it even exceeded $24 \%$ in those latter three. Those three have MDIs < -0.2 (Table 2), but their disparity is nevertheless not accurately predicted by an EB model. For shape, most simulated disparities are within $2 \%$ of the observed value and the median discrepancy is just $1.3 \%$. In three clades, the deviation is greater than $10 \%$ : Protoxerini (15\%), "Ammospermophilus" and "Ratufa" (22\%). We cannot fit more complex multipeak models to size or shape in these small clades; we presume that their disparities are not timedependent and therefore used their observed disparities when assessing the relationship between diversification and divergence. For the other clades, we used the model parameters to predict the time-invariant disparity that would accrue over $36 \mathrm{Myr}$ : 1000 trees were simulated using the trees function in the Diversitree package (FitzJohn 2012), and the median disparity of those simulations was used as the predicted disparity. Finally, to test for a 
correlation between size and shape, we used phylogenetic generalized least squares (PGLS), adapted to high-dimensional data (Adams 2014a), using the procD.pgls function in geomorph.

\section{STATISTICAL ANALYSIS OF CORRELATIONS}

Correlations between clade traits (size and shape disparities, species richness and speciation rate, clade age) were evaluated using a generalized least squares (GLS) approach to linear modeling as implemented in the $\mathrm{R}$ package nlme (Pinheiro et al. 2014) and supplemented with functions provided in Rabosky and Adams (2012) to incorporate phylogenetic branch lengths and a maximum likelihood estimate of Pagel's lambda $(\Lambda)$, a measure of phylogenetic signal (Pagel 1999). Branch lengths in units of time predict trait correlations under BM; those correlations are downweighted by multiplying off-diagonal elements of the variance-covariance matrix by $\Lambda$ in phylogenetic generalized least squares (PGLS). The value of $\Lambda$ ranges from 0 (no phylogenetic signal) to 1 (correlations equal to predictions under $\mathrm{BM})$. When $\Lambda=1$, the error matrix is that predicted by BM, and PGLS evaluates the likelihood of the observed correlations under that model. When $\Lambda=0$, PGLS is equivalent to conventional, nonphylogenetic GLS.

\section{Results}

\section{PHYLOGENETIC RELATIONSHIPS}

Our phylogeny (Fig. S1) broadly agrees with that of Fabre et al. (2012), particularly on the strongly supported nodes. Both analyses find that the major clades (ranked as subfamilies and tribes) are monophyletic. The main difference at these higher taxonomic levels is that our result supports a monophyletic group composed of Callosciurinae and Sciurinae, instead of placing these groups as successive sister groups to Xerinae. Our analysis also differs in finding support for the hypothesis that Ratufinae and Sciurillinae comprise a monophyletic group that is the sister group to all other extant Sciuridae. One area of apparent disagreement between the two results primarily reflects the misidentification of a sequence used to represent Tamias striatus in the study by Fabre et al. (2012); otherwise, the two studies agree on the monophyly of the western North American species (all except $T$. striatus and T. sibiricus). The remaining substantial difference within Tamias is that our analysis finds T. amoenus and T. siskiyou are successive sister groups to all other western North American species, not members of a lineage leading to the townsendii group. Another area of notable disagreement is the paraphyly of Sundasciurus with respect to several other genera of Callosciurinae. However, positions of Sundasciurus species with respect to each other on our tree are congruent with results of Fabre et al. (2012) and den Tex et al. (2010). Also, the genera intercalated among Sundasciurus in our result have the same relative positions as in Fabre et al. (2012):

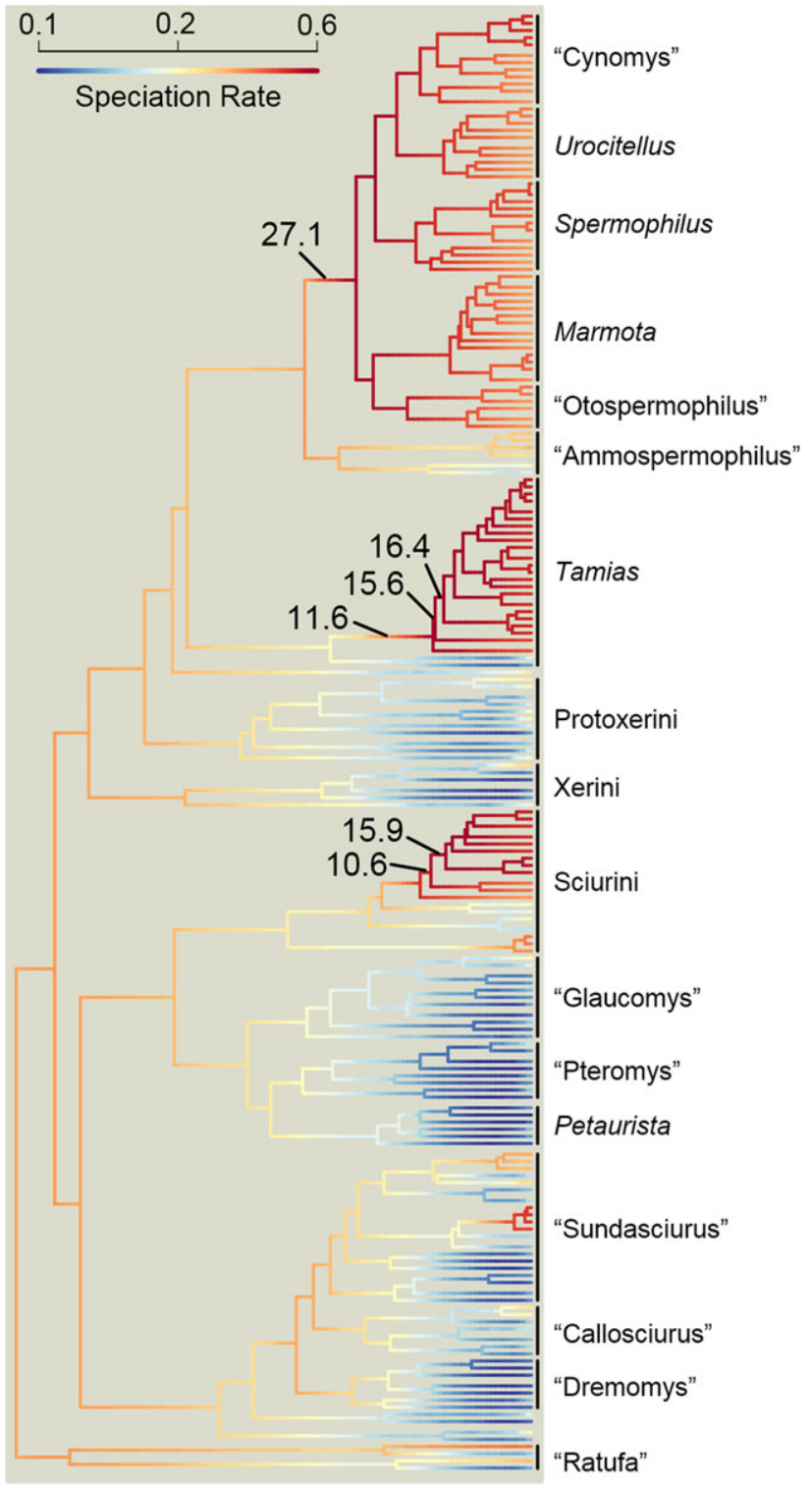

Figure 3. Speciation rate variation across clades and time. Vertical black lines indicate tips included in focal clades. Bayes factors (ratio of posterior to prior probability of rate regime shift) are indicated for the branches where the value is greater than 10 .

that is, Rubrisciurus and Prosciurillus are most closely related, followed by Hyosciurus, Nannosciurus, and then, Menetes and Rhinosciurus.

\section{LINEAGE DIVERSIFICATION RATES}

We used the topology and branching times of the phylogeny as the framework for inferring speciation rates. The best fitting speciation rate model describes a complex history of rate changes (Fig. 3). Speciation rates tend to be lower in the older Old World arboreal clades, and higher in the younger New World terrestrial clades. This pattern is best explained by three independent accelerations in (1) a lineage of North American tree squirrels (Sciurini), 
Table 3. Correlations among speciation rate, clade age, and species richness.

\begin{tabular}{clll}
\hline & $R$ & $\Lambda$ & $P$ \\
\hline $\begin{array}{c}\text { Speciation rate versus } \\
\text { crown age (Ma) }\end{array}$ & -0.447 & 0.000 & 0.072 \\
$\begin{array}{c}\text { Species richness (ln) } \\
\text { versus crown age } \\
\text { (Ma) }\end{array}$ & -0.136 & 1.000 & 0.482 \\
$\begin{array}{c}\text { Species richness (ln) } \\
\times \text { speciation rate }\end{array}$ & 0.158 & 0.008 & 0.536 \\
\hline
\end{tabular}

Speciation rates were computed from the rate model shown in Figure 3. $P$-values are given for phylogenetic generalized least squares with offdiagonal elements of the error matrix rescaled per Pagel's $\Lambda$.

(2) the western North American clade of chipmunks (Tamias), and (3) an early branch of marmotine ground squirrels (genera Callospermophilus to Cynomys and excluding Ammospermophilus and Notocitellus, see Fig. S1). The distribution of posterior probabilities suggest that the tree squirrel and chipmunk accelerations were distributed over several short branches, whereas the ground squirrel acceleration occurred entirely within a single, relatively long branch. Only the marmotine transition has a Bayes factor greater than 20 on a single branch (suggesting a high probability of transition on that branch); however, the other two transitions have Bayes factors greater than 10 on two or three consecutive branches, suggesting a high cumulative probability of transition within that time span.

Average speciation rates were computed for the 17 focal clades and tested for correlations with clade age and species richness (Table 3, Fig. S2). Mean speciation rate is not correlated with clade age. The oldest clades ("Ratufa" clade, Xerini) have lower average rates than the youngest clades (Marmota, Urocitellus), but clades of intermediate age span a broader range of rates. A consequence of this distribution of mean speciation rates across clades is that species richness also is not correlated with clade age. Clades of similar richness can differ greatly in age (e.g., "Ratufa" and "Otospermophilus"), and clades of similar age can differ greatly in richness (e.g., "Ammospermophilus" and "Sundasciurus"). Only the oldest clades ("Ratufa" and Xerini) lack counterparts that are similar in age but have substantially greater richness. Another consequence of this distribution of speciation rates across clade ages is that speciation rate also is not correlated with species richness; clades with similar mean rates span the range of species richness (cf., Xerini and "Otospermophilus" vs. Protoxerini and Sciurini).

\section{DISPARITY}

Miniature and giant squirrels evolved repeatedly, and many clades that include miniatures also contain exceptionally large-bodied species (Fig. S3). Miniaturization occurs repeatedly within the Asian tree squirrel lineage (e.g., Glyphotes, Exilisciurus, Nannosciurus) and twice within the largely New World tree squirrel lineage (Microsciurus). Although it is rare in the Holarctic ground squirrel clade, the two smallest chipmunks (T. minimus and T. alpinus) are within the size range of miniatures. Giants also evolved in multiple clades, although most giants are closely related (e.g., the giant flying squirrels, Petaurista, and the giant ground squirrels, Marmota).

About $45 \%$ of the variation in shape is described by $\mathrm{PC} 1$ (Fig. 4). Species with high positive scores on this axis (including several marmotines, Fig. S4) have a more posteriorly directed angular process, a narrower and more curved coronoid process, and a deeper notch between coronoid and condyloid processes than those with high negative scores (most Sciurinae). PC2 explains $19 \%$ of shape variation; species with high scores on this axis (which includes all miniatures other than the miniature flying squirrels) have relatively deep molar alveoli, a dramatically shortened coronoid process, and an elongated condyloid process. PC3 explains 14\% of the variation; species with high scores on this axis (most notably Rhinosciurus laticaudatus, a specialized insectivore in the "Sundasciurus" clade) have a relatively shallow mandible, a shallow and shortened angular process, and a relatively long distal condyloid process. In this morphospace, two groups stand out for the large areas of morphospace that they occupy. One is "Sundasciurus," which contains both R. laticaudatus and miniatures like Nannosciurus melanotis. Another is Protoxerini, which spans most of PC2. Another that stands out for very large distances between species is "Ratufa," which contains giants and miniatures and none between them. Several clades occupy very small ranges on all three PCs, and distances between species are also typically small, for example, Marmota, "Otospermophilus," and Petaurista. The phylomorphospace (Fig. 4) shows inferred ancestral shapes and evolutionary transformations, documenting convergence by branches that approach and even cross each other, although species that converge on only one or two axes might not otherwise closely resemble each other because $>20 \%$ of the variation is not within either plane. For example, two species that appear to be convergent in the PC1 versus PC3 plane are Trogopterus xanthipes and Xerus inauris, but they are simply convergent in their scores in this plane. Even though there is a clear separation of most of the major lineages on these three PCs, there is little phylogenetic signal in squirrel jaw shape; the multivariate Blomberg's $\mathrm{K}$ statistic is just 0.668 , below expectations from Brownian motion.

Size disparity ranges over nearly two orders of magnitude across clades and shape disparity by one (Table 4). Including species not present in the phylogenetic analysis typically lowers disparity, except that of size in Spermophilus. Not surprisingly, the two clades most disparate in size contain miniatures and giants 

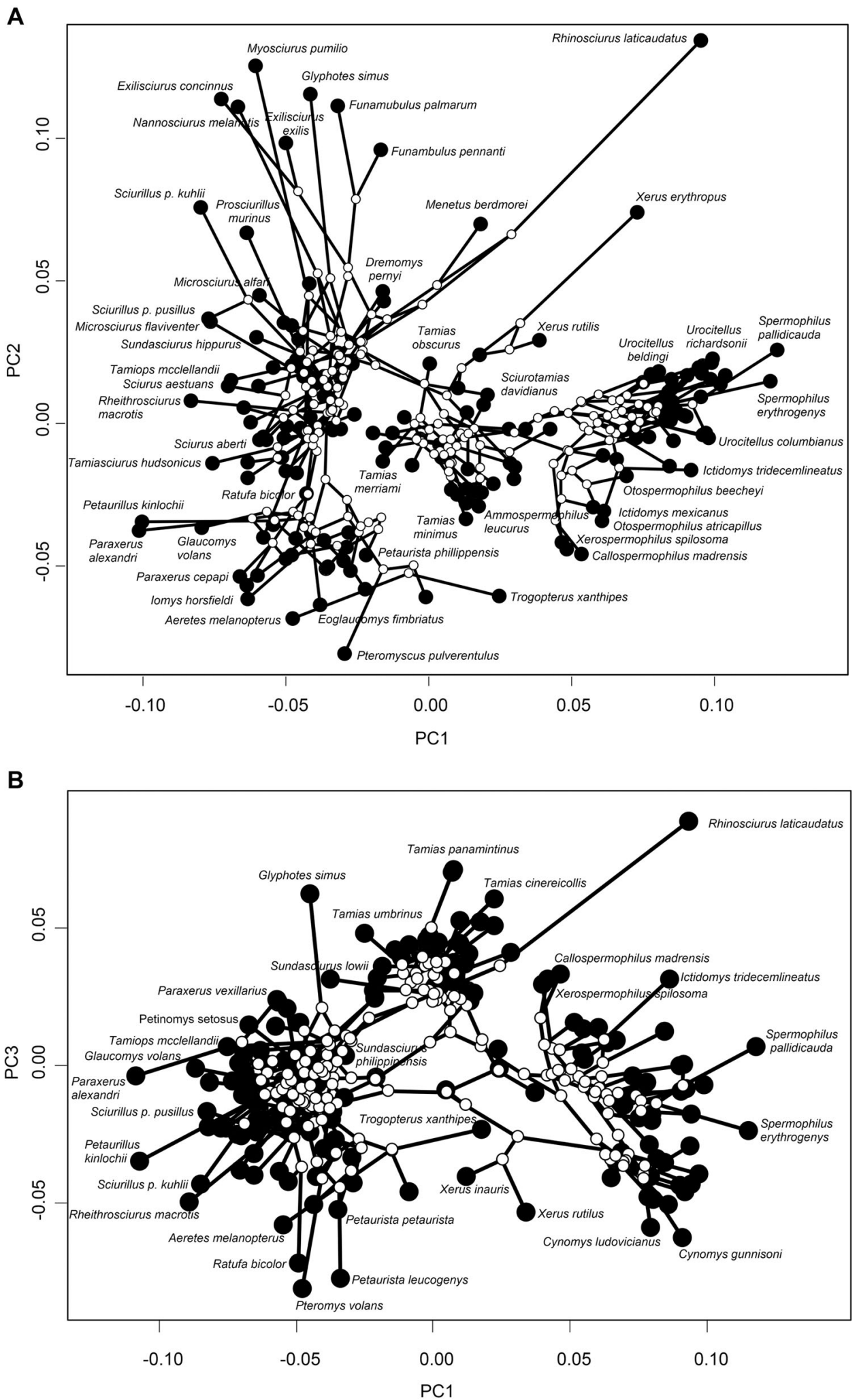

Figure 4. Phylogenetic relationships superimposed on shape PCs. (A) PC1 $\times$ PC2. (B) PC1 $\times$ PC3. Large black circles indicate scores of species means; smaller white circles are shapes inferred for nodes, using maximum likelihood optimization. 
Table 4. Disparities of size and shape for each clade.

\begin{tabular}{|c|c|c|c|c|}
\hline & \multicolumn{2}{|l|}{ Size } & \multicolumn{2}{|l|}{ Shape } \\
\hline & In Tree & Plus Added & In Tree & Plus Added \\
\hline “Cynomys" & 0.087577 & - & 0.003084 & - \\
\hline Urocitellus & 0.020359 & - & 0.001009 & - \\
\hline Spermophilus & 0.010561 & 0.01105 & 0.001821 & 0.00168 \\
\hline Marmota & 0.004334 & - & 0.000858 & - \\
\hline "Otospermophilus" & 0.033467 & - & 0.001109 & - \\
\hline "Ammospermophilus" & 0.035599 & - & 0.002254 & - \\
\hline Tamias & 0.007250 & - & 0.001151 & - \\
\hline Protoxerini & 0.159170 & 0.11111 & 0.006457 & 0.00517 \\
\hline Xerini & 0.008127 & - & 0.003916 & - \\
\hline Sciurini & 0.054660 & 0.04619 & 0.001987 & 0.00171 \\
\hline "Glaucomys" & 0.079848 & - & 0.002412 & - \\
\hline "Pteromys" & 0.077232 & - & 0.003789 & - \\
\hline Petaurista & 0.003956 & - & 0.000979 & - \\
\hline "Sundasciurus" & 0.079687 & 0.07513 & 0.005425 & 0.00528 \\
\hline "Callosciurus" & 0.078449 & 0.06772 & 0.003445 & 0.00310 \\
\hline "Dremomys" & 0.035797 & - & 0.001578 & - \\
\hline "Ratufa" & 0.333728 & - & 0.005113 & - \\
\hline
\end{tabular}

For both size and shape, estimates based only on species in the tree (In Tree) are followed by estimates based on all measured species (Plus Added).

Table 5. Tests for correlation of size and shape disparities to each other and to clade age.

\begin{tabular}{llll}
\hline & $R$ & $\Lambda$ & $P$ \\
\hline Shape $\times$ size & 0.695 & 0.354 & 0.003 \\
Size $\times$ crown age $(\mathrm{Ma})$ & 0.724 & 0.119 & 0.001 \\
Shape $\times$ crown age $(\mathrm{Ma})$ & 0.670 & 1.000 & 0.015 \\
\hline
\end{tabular}

P-values are given for phylogenetic generalized least squares with offdiagonal elements of the error matrix rescaled per Pagel's $\Lambda$.

("Ratufa," Protoxerini) and some of the least disparate in size contain only giants (Marmota, Petaurista) or neither miniatures nor giants (Spermophilus, Xerini). The most disparate is Protoxerini when considering only the species included in the phylogeny; considering all sampled species, Protoxerini and "Sundasciurus" are the most disparate. "Sundasciurus" is so disparate in shape primarily because it contains the highly divergent $R$. laticaudatus and the somewhat less divergent Menetes berdmorei, as well as some miniatures and one very large-bodied species. The clades that are least disparate in shape are the same ones that are least disparate in size, Marmota and Petaurista.

\section{CORRELATIONS AMONG DISPARITY, DIVERSITY, AND AGE}

Disparities of size and shape are correlated with each other and with clade age (Table 5), although some older clades are not well predicted by the general relationship between size and shape
Table 6. Tests for correlation of size and shape disparities to species richness and average speciation rate.

\begin{tabular}{lrll}
\hline & \multicolumn{1}{l}{$R$} & $\Lambda$ & $P \Lambda$ \\
\hline Size disparity $\times$ species richness $(\ln )$ & -0.061 & 0.000 & 0.815 \\
Size disparity $\times$ speciation rate & -0.292 & 0.000 & 0.256 \\
Shape disparity $\times$ species richness $(\ln )$ & 0.162 & 0.000 & 0.534 \\
Shape disparity $\times$ speciation rate & -0.512 & 1.000 & 0.206 \\
\hline
\end{tabular}

$P$-values are given for phylogenetic generalized least squares with offdiagonal elements of the error matrix rescaled per Pagel's $\Lambda$.

disparities (Fig. 5), "Ratufa" is below the predicted ratio of shape/size disparity; Xerini, "Sundasciurus," and Protoxerini are above it (Fig. 5A). These deviations may have different evolutionary origins because "Ratufa" has high size disparity for its age and Xerini has low size disparity for its age (Fig. 5B); "Sundasciurus" and Protoxerini have high shape disparities for their ages (Fig. 5C). Neither size nor shape disparity is correlated with species richness or speciation rate (Table 6). Species-rich clades and species-poor clades generally span similar ranges of size and shape disparity; the main exception is "Ratufa," which has twice the size disparity of any other clade (Fig. 6). Likewise, rapidly speciating and slowly speciating clades generally span similar shape disparities. Three slowly speciating clades ("Sundasciurus," "Ratufa," and Protoxerini) have relatively high shape disparities, but the relationship between speciation rate and shape disparity is not significant when phylogeny is taken into account. Although 
A

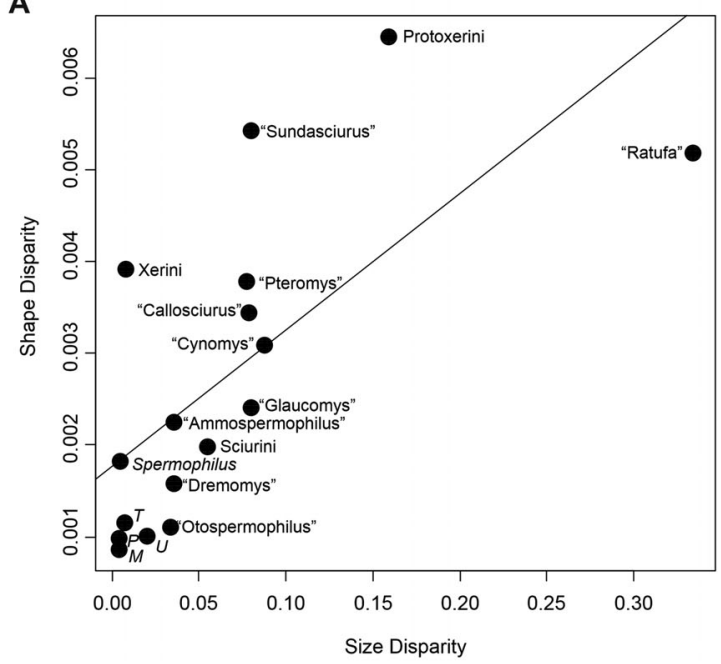

B

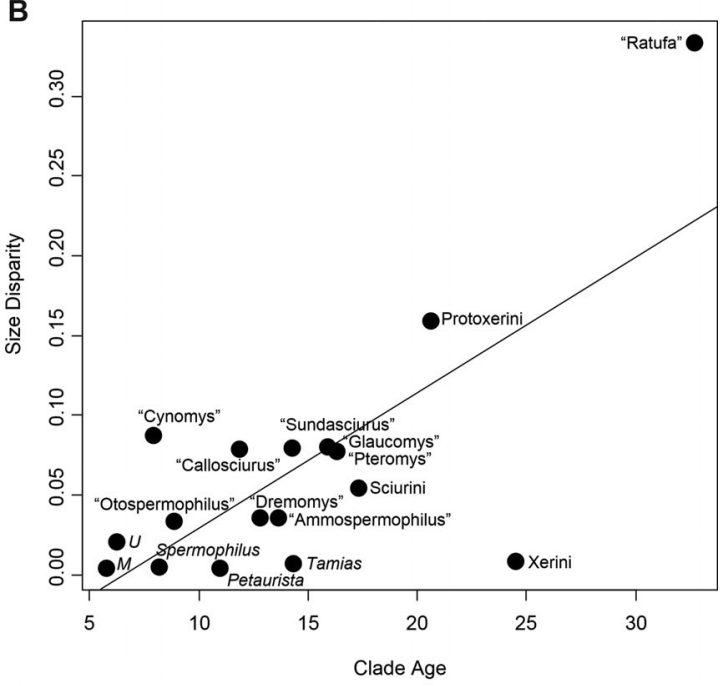

C

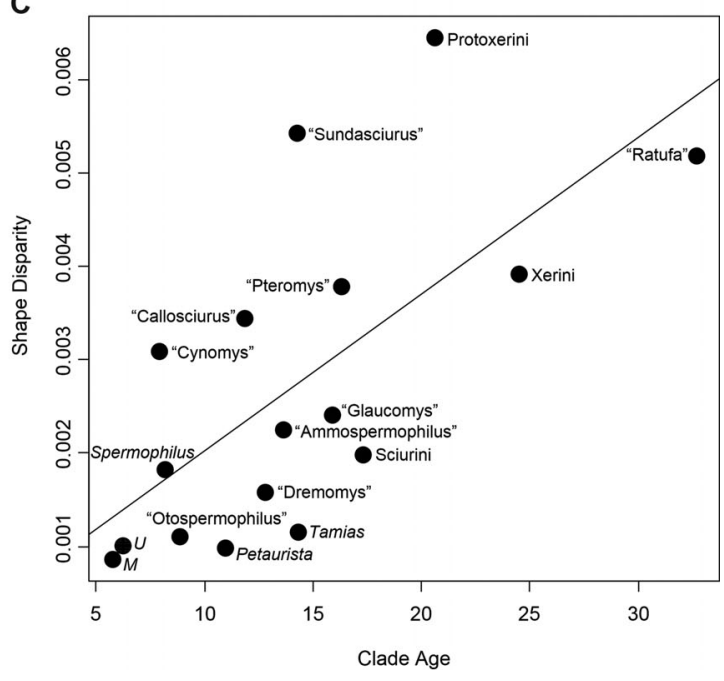

Figure 5. Size and shape disparities in relation to each other (A) and to clade age $(B, C)$. The best fitting line is shown for each analysis. M, Marmota; P, Petaurista; T, Tamias; U, Urocitellus. Values of $R$ and $P$ are given in Table 5. size and shape disparities are correlated with each other, size and shape are only weakly related; evolutionary allometry is statistically significant $\left(F_{1,166}=9.64, P=0.001\right]$ but size explains only $5.5 \%$ of the disparity of shape.

\section{EVOLUTIONARY MODE AND RATE}

The strength of the pull to the optimum $(\alpha)$ varies considerably across clades (Table 7). For size, it is typically weak and several clades fit a BM model ("Otospermophilus," Petaurista, "Pteromys," "Ratufa," "Ammospermophilus," Tamias, and Xerini) rather than an SSP model. For the others, we can estimate the time required to reach half-way to the optimum, that is, the phylogenetic half-life, estimated by $(\ln 2) / \alpha$ (Hansen 1997; Hansen et al. 2008). For several clades, the phylogenetic halflife is short not only relative to clade age but also relative to the most recent branching event (Marmota, Urocitellus, "Glaucomys," "Callosciurus," "Pteromys") (Table 7). For clades that have evolved in a constant niche over a long time, the expected equilibrium variance of the Ornstein-Uhlenbeck process is $\sigma^{2} / 2 \alpha$ (Hansen 1997; Hansen et al. 2008), and the observed size disparities are very close to the expected equilibrium disparity. But in several clades, size has not evolved to a constant niche over a long time. For shape, the phylogenetic half-life is approximately $2-6 \%$ of crown age, except in the cases of Xerini and the three clades that fit no simple model well (Protoxerini, "Sundasciurus," Petaurista). For several clades, phylogenetic half-life is less than $50 \%$ of the age of the youngest branch ("Callosciurus," "Dremomys," "Pteromys," "Otospermophilus," "Cynomys," Marmota, Xerini) or just slightly greater than that (Spermophilus, Urocitellus, "Glaucomys"). Not surprisingly, the predicted equilibrium variance is typically close to the observed disparity.

For both size and shape, the median disparities simulated over 36 Myr are very similar to observed ones (Fig. S5) although discrepancies are larger for size, especially for two clades ("Cynomys" and "Pteromys"). Nevertheless, the best fitting lines for the regression of the observed on time-invariant (simulated) disparities have a slope near 1 and an intercept near 0 . The close correspondence between disparities simulated over $36 \mathrm{Myr}$ and the observed disparities, which evolved over much shorter time scales, suggest that time scale of divergence has little impact on disparity, especially for shape. Not surprisingly, like the observed disparities of size and shape, time-invariant disparities of size and shape are correlated with each other (Table 8) and both are correlated with clade age but not with species richness or speciation rate.

\section{Discussion}

Several hypotheses predict that diversification and divergence patterns should be related either indirectly or directly but several 
Table 7. Crown age (CA) and age of the most recent branching event (MRB) in Ma, with estimates of the pull to the optimum ( $\alpha$ ), Brownian rate $\left(\sigma^{2}\right)$, phylogenetic half-life $(H L=[\ln 2] / \alpha)$, and equilibrium variance $\left(E V=\sigma^{2} / 2 \alpha\right)$ for size and shape, and the observed variance (OBS) computed from the PCs used to estimate the model.

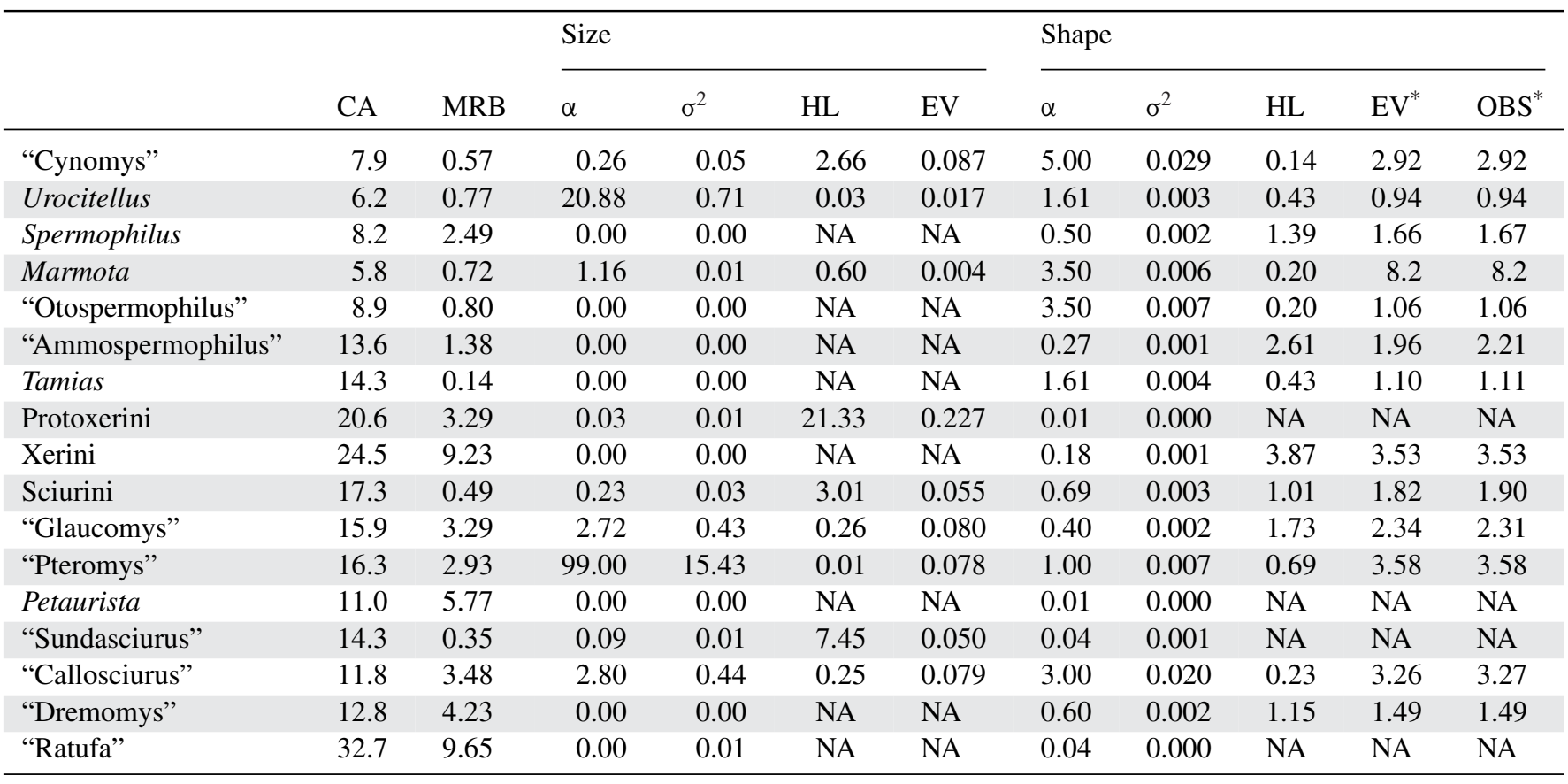

*Values in the last two columns have been multiplied by $10^{3}$.

Table 8. Correlations of median simulated (MS) size and shape disparities to each other and to clade age, species richness, and average speciation rate.

\begin{tabular}{lrll}
\hline & $R$ & $\Lambda$ & $P \Lambda$ \\
\hline MS size disparity $\times$ MS shape disparity & 0.665 & 1.000 & 0.024 \\
MS size disparity $\times$ crown age (Ma) & 0.749 & 0.204 & 0.001 \\
MS size disparity $\times$ species richness (ln) & 0.017 & 0.000 & 0.947 \\
MS size disparity $\times$ speciation rate & -0.311 & 0.000 & 0.225 \\
MS shape disparity $\times$ crown age $(\mathrm{Ma})$ & 0.625 & 1.000 & 0.032 \\
MS shape disparity $\times$ species richness $(\mathrm{ln})$ & 0.192 & 0.000 & 0.461 \\
MS shape disparity $\times$ speciation rate & -0.552 & 1.000 & 0.161 \\
\hline
\end{tabular}

$P$-values are given for phylogenetic generalized least squares with off-diagonal elements of the error matrix rescaled per Pagel's $\Lambda$.

others predict that they are unlikely to be related, especially in global radiations that span multiple continents and undergo geographically and/or temporally iterated adaptive plus nonadaptive radiations. In our analysis of a nearly globally distributed clade of squirrels, which has diversified on all continents save Australia and Antarctica, we find that patterns of diversification are uncorrelated with morphological divergence. They are unrelated regardless of whether patterns of diversification are measured by speciation rates or species richness, and whether patterns of divergence are measured by a time-invariant disparity or disparity itself. Disparity and richness could be related simply because both take time to accrue, but in these clades species richness is not related to crown age. Disparity of both size and shape appear to be related to crown age largely because some young, rapidly diversifying Neartic clades of ground squirrels are strongly pulled to a single stable optimum, whereas more slowly diversifying old Paleotropical clades include lineages that diverge along multiple ecological and morphological lines. Although there are some striking contrasts in the disparities of size and jaw shape, they show similar patterns except that size is more rarely constrained to a single stable peak than is jaw shape.

Part of the explanation for the contrast between young, morphologically homogeneous Nearctic clades and older, disparate Paleotropical clades is our subdivision of a highly asymmetric tree into the maximum number of nonoverlapping lineages containing four or more species. Because of their higher speciation rate, the 
young Nearctic clades comprise species separated by very short times compared to more slowly speciating (and sometimes undersampled) Paleotropical clades. However, except for the consequences of undersampling, this contrast between young Nearctic clades and older Paleotropical ones is not simply a methodological artifact-it is due to a greater number of species being separated by very short times in the rapidly diversifying Nearctic lineages. That some rapidly diversifying clades are so strongly pulled to a single adaptive peak, whereas some slowly diversifying ones diverge along multiple ecological and morphological lines is not a methodological artifact - it is what requires an explanation.

That contrast between clades is probably due, in part, to the environments they inhabit and, in part, to their phylogenetic community structure. The multilayered Paleotropical rainforest environments are famously complex structurally (Lowman and Moffett 1993; Richards 1996) and they are also more heterogeneous in resources than Nearctic temperate forests. The community of diurnal squirrels inhabiting the Paleotropical rainforest typically contains four or even five trophic ecomorphs: (1) miniature bark-gleaners; (2) large to giant hard-endocarp specialists; (3) frugivores that eat pulpy fruit plus moderately large, hard seeds and insects; (4) small-seed eaters that also eat insects as well as fruits that fall to the ground; and (5) specialized insectivores. Nearctic forests lack the multilayered canopy and hard-endocarp producing trees of Paleotropical rainforests. Thus, Nearctic forests contain a different array of ecomorphs than Paleotropical rainforests, lacking both hard-endocarp specialists and miniature bark-gleaners. Nearctic forests, however, do typically contain an ecomorph not found in Paleotropical forests: giant specialized grazers. There are dietary specialists in Nearctic forests, such as pine-cone specialists and fungivores, but they are not extreme in either jaw morphology or size. The squirrel communities of savannas and arid regions of western North America are less disparate ecologically and in jaw morphology, which is not surprising because treeless areas lack tree squirrels, and it is the coexistence of tree and ground squirrels that makes forest communities so disparate. Savanna communities commonly contain two seed-eating ground squirrel species plus one or two grazers; desert communities contain one or two seed-eating ground squirrel species.

The contrast among environments, however, does not fully explain the variation in disparity among clades. The Nearctic forest communities are also remarkably disparate in jaw morphology, spanning nearly the total extent of the first principal component of jaw shape (Fig. 4). But the Nearctic forest lineages are not disparate. What makes the African Paleotropical Protoxerini so disparate is that ecomorphs coexist in the western African rainforest of Gabon (Emmons 1980) and all belong to Protoxerini, a lineage of 31 species that began to diversify approximately $20 \mathrm{Ma}$. Even the recent (7.5 Ma) Sulawesi radiation of just 10 species produced all ecomorphs but the highly specialized in- sectivore (the nearest analog, Hyosciurus, can also eat seeds). Throughout much of peninsular Malaysia and the larger Sundaland islands, all five Paleotropical ecomorphs can also be found (Harrison 1962; MacKinnon 1978; Payne 1980), although not all belong to our "Sundasciurus" clade. That clade is so disparate largely because it contains the most divergent squirrels, the specialized insectivore, $R$. laticaudatus, that converge on a tree shrew. In contrast, the high disparity of Nearctic forest squirrel communities results from the coexistence of distantly related tree and ground squirrels whose ancestor lived approximately $34 \mathrm{Ma}$. The North American tree squirrels did not descend to the ground and when the Marmotina arrived in North America, they did not ascend to the trees perhaps because the incumbent tree squirrels already occupied them.

Size and shape disparity are highly correlated in squirrels even though size and shape are only weakly related. That correlation of disparities is due, in part, to the striking contrast between miniature bark-gleaners and giant hard-endocarp specialists. Clades that contain both ecomorphs are the most disparate in both size and shape. Clades that contain only one trophic ecomoph and one size class, such as giant specialized folivores (Petaurista) or giant grazers (Marmota), are the least disparate in both size and shape. But size disparity does not result solely from the distinctive sizes of ecomorphs. Size is sometimes disparate because trophic morphology is not. When trophically similar species coexist, as in the African rainforest of Gabon, they either occupy different heights within the canopy or they differ in size by Hutchinson's ratio (Emmons 1980); that ratio (approximately 1.3 for lengths) is the difference necessary to permit coexistence at the same level of a food web (Hutchinson 1959). That species with the same trophic niche can diverge either in canopy height or size may explain the more complex dynamics of size evolution compared to the divergence of shape; size is less tightly constrained to a single optimum than is shape.

The contrast between rapidly diversifying, morphologically homogenous clades and slowly diversifying, morphologically disparate ones is as much an outcome of the difference in diversification rates as it is of the difference in disparity. The Nearctic clades are not only homogeneous morphologically, they are also rapidly diversifying. High speciation rates in western North America may be an instance of a more general longitudinal gradient in species richness due to acceleration of diversification rates in this tectonically and climatically complex region that occurred approximately 18-16 Ma (Barnosky and Carrasco 2002; Badgley 2010; Finarelli and Badgley 2010; Badgley and Finarelli 2013; KentCorson et al. 2013). The close link between geological history and global patterns of squirrel diversification was first revealed in the seminal study by Mercer and Roth (2003). More recent studies have focused on the link between geological history and the timing of speciation in particular groups, often documenting an 

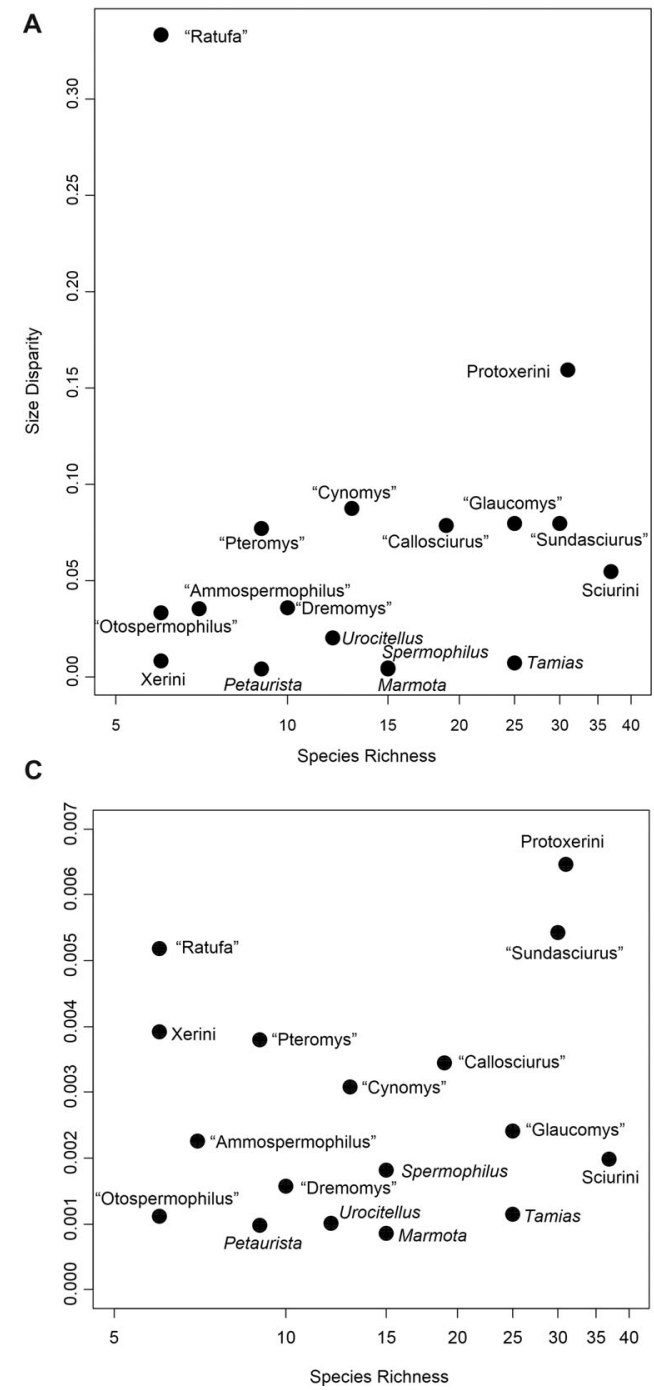
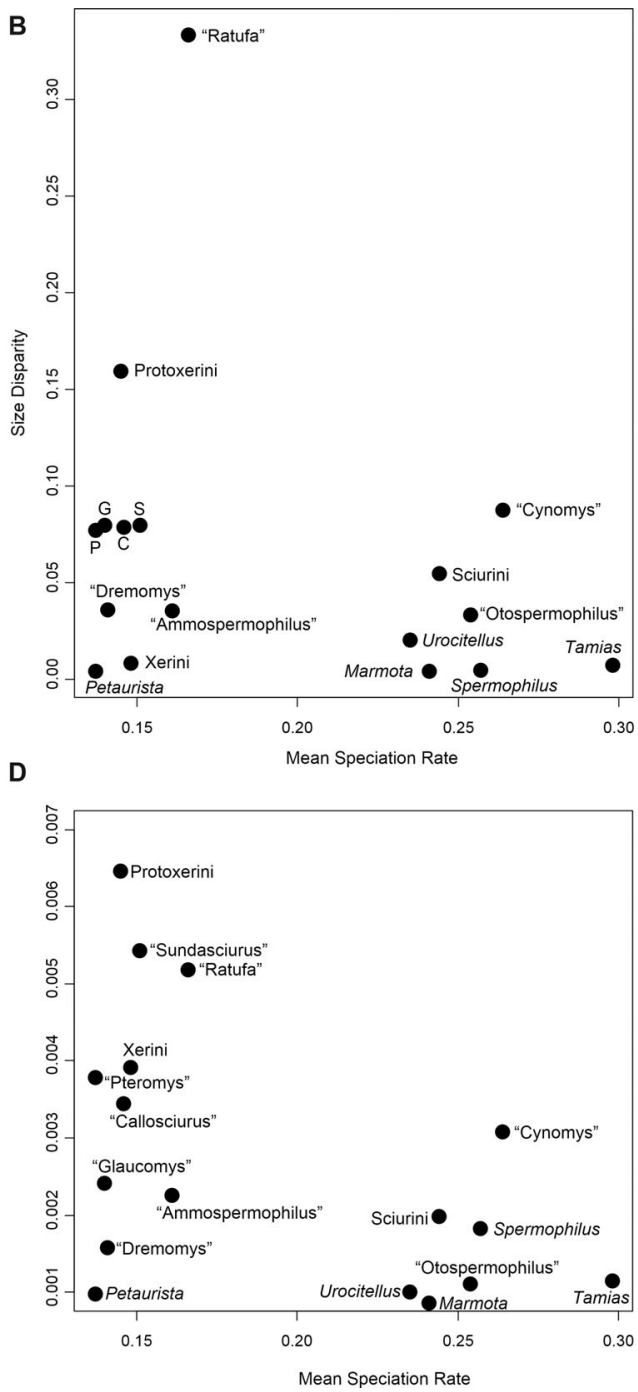

Figure 6. Size disparity (A, B) and shape disparity (C, D) are not correlated with species richness (A, C) or diversification rate (B, D). P, "Pteromys"; G, "Glaucomys"; C, "Callosciurus"; $S$, "Sundasciurus." Values of $R$ and $P$ are given in Table 6.

unexpectedly old age of many divergences (den Tex et al. 2010). The timing of particular radiations has been linked to environmental changes that promote diversification, such as grassland expansion in Miocene western North America, corresponding to the timing of the radiation of North American Marmotini (Harrison et al. 2003; Ge et al. 2014), and the subdivisions of southwestern deserts by growth of the Basin and Range province, isolating the species that inhabit them (Bell et al. 2010; Mantooth et al. 2013). Similarly, Pleistocene glacial-interglacial cycles have been linked to the very recent speciation events of young clades, such as the origin of T. alpinus (Rubidge et al. 2014).

Our finding that patterns of diversification and divergence are not related to each other differs from that of two previous studies that analyzed per lineage diversification and divergence, finding them to be correlated. One found per lineage species richness to be correlated with per lineage rates of phenotypic evolution in Plethodon salamanders (Rabosky and Adams 2012), and the other found that per lineage rates of diversification are correlated with per lineage rates of body-size evolution in actinopterygians (Rabosky et al. 2013). Several hypotheses were considered that might explain that correlation, including that divergence results from speciation, or that the capacity to produce novel morphologies and ecologies itself promotes speciation, or that character displacement is most common in species rich clades and therefore such clades should be most disparate. None of these scenarios can account for the patterns seen in squirrels, because the most rapidly diversifying clades exhibit the strongest pulls to a persistent optimum and more slowly diversifying clades include the ecologically and morphologically most disparate ones. Our results instead argue for ecologically mediated modes of phenotypic evolution and geographically mediated modes of speciation. 
Discrepancies between ecologically mediated modes of phenotypic evolution and geographically mediated modes of speciation may be common, explaining why early bursts of divergence and diversification are rare. Diversification and divergence will be uncorrelated when adaptive and geographic landscapes do not coincide, as in nonadaptive radiations that are characterized by persistent primary optima and high speciation rates. These may be localized to regions where species adapt to a broadly distributed resource within a dynamic geographic landscape. The habitat fragments but the resource, and primary optimum, persists (as when islands are divided by rising sea level but the same forest community is present on each one). Adaptive and geographic landscapes also do not coincide when environments are heterogeneous but geographic landscapes are stable. Lacking incumbents, such environments would promote rapid divergence along multiple ecological lines but speciation may proceed at unexceptional rates. In squirrels, and perhaps in most broadly distributed clades, adaptive and geographic landscapes do not coincide.

\section{ACKNOWLEDGMENTS}

We thank the curators and staff of UMMZ, MVZ, US NMNH, CUMV, and FMNH for access to the specimens in their care. We thank P. H. Fabre and colleagues for generously sharing the sequence data used in their study, G. Slater for generously sharing the code for the multivariate version of the fitContinuous function (fitContinuousMV), and J. Cooper for photographing specimens at CUMV. LAPT was supported by a National Science Foundation Graduate Research Fellowship; JL was supported by a University of Michigan Rackham Predoctoral Fellowship. We also thank C. Badgley for helpful comments on the manuscript, and M. Alfaro and two anonymous reviewers for insightful comments and suggestions that greatly improved the manuscript.

\section{DATA ARCHIVING}

The doi for our data is $10.5061 /$ dryad.kq1g6.

\section{LITERATURE CITED}

Adams, D. C. 2014a. A method for assessing phylogenetic least squares models for shape and other high-dimensional multivariate data. Evolution 68:2675-2688.

. 2014b. Quantifying and comparing phylogenetic evolutionary rates for shape and other high-dimensional phenotypic data. Syst. Biol. 63:166-177.

Adams, D. C., and E. Otarola-Castillo. 2013. geomorph: an R package for the collection and analysis of geometric morphometric shape data. Methods Ecol. Evol. 4:393-399.

Adams, D. C., C. M. Berns, K. H. Kozak, and J. J. Wiens. 2009. Are rates of species diversification correlated with rates of morphological evolution? Proc. R. Soc. Lond. B 276:2729-2738.

Alfaro, M. E., C. D. Brock, B. L. Banbury, and P. C. Wainwright. 2009a. Does evolutionary innovation in pharyngeal jaws lead to rapid lineage diversification in labrid fishes? BMC Evol. Biol. 9:255. doi: 10.1186/14712148-9-255

Alfaro, M. E., F. Santini, C. Brock, H. Alamillo, A. Dornburg, D. L. Rabosky, G. Carnevale, and L. J. Harmon. 2009b. Nine exceptional radiations plus high turnover explain species diversity in jawed vertebrates. Proc. Natl. Acad. Sci. USA 106:13410-13414.
Allman, E. S., C. Ane, and J. A. Rhodes. 2008. Identifiability of a Markovian model of molecular evolution with gamma-distributed rates. Adv. Appl. Prob. 40:229-249.

Badgley, C. 2010. Tectonics, topography, and mammalian diversity. Ecography 33:220-231.

Badgley, C., and J. A. Finarelli. 2013. Diversity dynamics of mammals in relation to tectonic and climatic history: comparison of three Neogene records from North America. Paleobiology 39:373-399.

Barnosky, A. D., and M. A. Carrasco. 2002. Effects of Oligo-Miocene global climate changes on mammalian species richness in the northwestern quarter of the USA. Evol. Ecol. Res. 4:811-841.

Bell, K. C., D. J. Hafner, P. Leitner, and M. D. Matocq. 2010. Phylogeography of the ground squirrel subgenus Xerospermophilus and assembly of the Mojave Desert biota. J. Biogeogr. 37:363-378.

Bookstein, F. L. 1997. Landmark methods for forms without landmarks: morphometrics of group differences in outline shape. Med. Image Anal. $1: 225-243$.

Burbrink, F. T., X. Chen, E. A. Myers, M. C. Brandley, and R. A. Pyron. 2012a. Evidence for determinism in species diversification and contingency in phenotypic evolution during adaptive radiation. Proc. R. Soc. Lond. B 279:4817-4826.

Burbrink, F. T., S. Ruane, and R. A. Pyron. 2012b. When are adaptive radiations replicated in areas? Ecological opportunity and unexceptional diversification in West Indian dipsadine snakes (Colubridae: Alsophiini). J. Biogeogr. 39:465-475.

Claramunt, S., E. P. Derryberry, R. T. Brumfield, and J. V. Remsen. 2012. Ecological opportunity and diversification in a continental radiation of birds: climbing adaptations and cladogenesis in the Furnariidae. Am. Nat. 179:649-666.

Cooper, W. J., and M. W. Westneat. 2009. Form and function of damselfish skulls: rapid and repeated evolution into a limited number of trophic niches. BMC Evol. Biol. 9:17. doi:10.1186/1471-2148-9-24.

den Tex, R. J., R. Thorington, J. E. Maldonado, and J. A. Leonard. 2010. Speciation dynamics in the SE Asian tropics: putting a time perspective on the phylogeny and biogeography of Sundaland tree squirrels, Sundasciurus. Mol. Phyl. Evol. 55:711-720.

Dornburg, A., B. Sidlauskas, F. Santini, L. Sorenson, T. J. Near, and M. E. Alfaro. 2011. The influence of an innovative locomotor strategy on the phenotypic diversification of triggerfish (family: Balistidae). Evolution 65:1912-1926.

Drummond, A. J., M. A. Suchard, D. Xie and A. Rambaut. 2012. Bayesian phylogenetics with BEAUti and the BEAST 1.7. Mol. Biol. Evol. 29:19691973.

Edgar, R. C. 2004. MUSCLE: multiple sequence alignment with high accuracy and high throughput. Nucl. Acids Res. 32:1792-1797.

Emmons, L. H. 1980. Ecology and resource partitioning among nine species of African rain-forest squirrels. Ecol. Monogr. 50:31-54.

Emry, R. J., and W. W. Korth. 2007. A new genus of squirrel (Rodentia, Sciuridae) from the mid-Cenozoic of North America. J.Vert. Paleo. 27:693698.

Emry, R. J., and R. W. Thorington, Jr. 1982. Descriptive and comparative osteology of the oldest fossil squirrel. Smith. Contrib. Paleont. 47:1-34

1984. The tree squirrel Sciurus (Sciuridae, Rodentia) as a living fossil. Pp. 23-31 in N. Eldredge and S. M. Stanley, eds. Living fossils. Springer-Verlag, New York.

Etienne, R. S., and B. Haegeman. 2012. A conceptual and statistical framework for adaptive radiations with a key role for diversity dependence. Am. Nat. 180:E75-E89.

Fabre, P. H., L. Hautier, D. Dimitrov, and E. J. P. Douzery. 2012. A glimpse on the pattern of rodent diversification: a phylogenetic approach. BMC Evol. Biol. 12. doi: 10.1186/1471-2148-12-88. 
Finarelli, J. A., and C. Badgley. 2010. Diversity dynamics of Miocene mammals in relation to the history of tectonism and climate. Proc. R. Soc. Lond. B 277:2721-2726.

FitzJohn, R. G. 2012. Diversitree: comparative phylogenetic analyses of diversification in R. Methods Ecol. Evol. 3:1084-1092.

Freckleton, R. P., and P. H. Harvey. 2006. Detecting non-Brownian trait evolution in adaptive radiations. PLOS Biol. 4:e373.

Frederich, B., L. Sorensen, F. Santini, G. J. Slater, and M. E. Alfaro. 2013. Iterative ecological radiation and convergence during the evolutionary history of damselfishes (Pomacentridae). Am. Nat. 181:94-113.

Ge, D. Y., X. Liu, X. F. Lv, Z. Q. Zhang, L. Xia, and Q. S. Yang. 2014. Historical biogeography and body form evolution of ground squirrels (Sciuridae: Xerinae). Evol. Biol. 41:99-114.

Gittenberger, E. 1991. What about non-adaptive radiation. Biol. J. Linn. Soc. 43:263-272.

Green, W. D. K. 1996. The thin-plate spline and images with curving features. Pp. 79-87 in K. V. Mardia, C. A. GillandI, and L. Dryden, eds. Image fusion and shape variability. University of Leeds Press, Leeds, U.K.

Hansen, T. F. 1997. Stabilizing selection and the comparative analysis of adaptation. Evolution 51:1341-1351.

Hansen, T. F., and E. P. Martins. 1996. Translating between microevolutionary process and macroevolutionary patterns: the correlation structure of interspecific data. Evolution 50:1404-1417.

Hansen, T. F., P. Jason, and S. H. Orzack. 2008. A comparative method for studying adaptation to a randomly evolving environment. Evolution 62:1965-1977.

Harmon, L. J., J. A. Schulte, A. Larson, and J. B. Losos. 2003. Tempo and mode of evolutionary radiation in iguanian lizards. Science 301:961964.

Harmon, L. J., J. T. Weir, C. D. Brock, R. E. Glor, and W. Challenger. 2008. GEIGER: investigating evolutionary radiations. Bioinformatics 24:129131.

Harrison, J. L. 1962. The distribution of feeding-habits among animals in a tropical rain-forest. J. Anim. Ecol. 31:53-63.

Harrison, R. G., S. M. Bogdanowicz, R. S. Hoffman, E. Yensen, and P. W. Sherman. 2003. Phylogeny and evolutionary history of the ground squirrels (Rodentia: Marmotinae). J. Mamm. Evol. 10:249-276.

Hayssen, V. 2008. Patterns of body size and tail length and body mass in Sciuridae. J. Mamm. 89:852-873.

Hunt, G. 2012. Measuring rates of phenotypic evolution and the inseparability of tempo and mode. Paleobiology 38:351-373.

Hutchinson, G. E. 1959. Homage to Santa Rosalia or why are there so many kinds of animals? Am. Nat. 93:145-159.

Kembel, S. W., P. D. Cowan, M. R. Helmus, W. K. Cornwell, H. Morlon, D. D. Ackerly, S. P. Blomberg, and C. O. Webb. 2010. Picante: R tools for integrating phylogenies and ecology. Bioinformatics 26:1463-1464.

Kent-Corson, M. L., A. D. Barnosky, A. Mulch, M. A. Carrasco, and C. P. Chamberlain. 2013. Possible regional tectonic controls on mammalian evolution in western North America. Paleogeogr. Paleoclimatol. Paleoecol. 387:17-26.

Klingenberg, C. P., and G. S. McIntyre. 1998. Geometric morphometrics of developmental instability: analyzing patterns of fluctuating asymmetry with Procrustes methods. Evolution 52:1363-1375.

Kozak, K. H., D. W. Weisrock, and A. Larson. 2006. Rapid lineage accumulation in a non-adaptive radiation: phylogenetic analysis of diversification rates in eastern North American woodland salamanders (Plethodontidae: Plethodon). Proc. R. Soc. Lond. B 273:539-546.

Lanfear, R., B. Calcott, S. Y. W. Ho, and S. Guindon. 2012. PartitionFinder: combined selection of partitioning schemes and substitution models for phylogenetic analyses. Mol. Biol. Evol. 29:1695-1701.
Lovette, I. J., E. Bermingham, and R. E. Ricklefs. 2002. Clade-specific morphological diversification and adaptive radiation in Hawaiian songbirds. Proc. R. Soc. Lond. B 269:37-42.

Lowman, M. D., and M. Moffett. 1993. The ecology of tropical rain forest canopies. Trends Ecol. Evol. 8:104-107.

MacKinnon, K. S. 1978. Stratification and feeding differences among Malayan squirrels. Malay. Nat. J. 30:593-608.

Mahler, D. L., L. J. Revell, R. E. Glor, and J. B. Losos. 2010. Ecological opportunity and the rate of morphological evolution in the diversification of Greater Antillean anoles. Evolution 64:2731-2745.

Mahler, D. L., T. Ingram, L. J. Revell, and J. B. Losos. 2013. Exceptional convergence on the macroevolutionary landscape in island lizard radiations. Science 341:292-295.

Mantooth, S. J., D. J. Hafner, R. W. Bryson, and B. R. Riddle. 2013. Phylogeographic diversification of antelope squirrels (Ammospermophilus) across North American deserts. Biol. J. Linn. Soc. 109:949-967.

Martins, E. P. 1994. Estimating the rate of phenotypic evolution from comparative data. Am. Nat. 144:193-209.

Mattila, T. M., and F. Bokma. 2008. Extant mammal body masses suggest punctuated equilibrium. Proc. R. Soc. Lond. B 275:2195-2199.

McPeek, M. A., and J. M. Brown. 2007. Clade age and not diversification rate explains species richness among animal taxa. Am. Nat. 169:E97-E106.

McPeek, M. A., L. Shen, J. Z. Torrey, and H. Farid. 2008. The tempo and mode of three-dimensional morphological evolution in male reproductive structures. Am. Nat. 171:E158-E178.

Mercer, J. M., and V. L. Roth. 2003. The effects of Cenozoic global change on squirrel phylogeny. Science 299:1568-1572.

O'Meara, B. C. 2006. Testing for different rates of continuous trait evolution using likelihood. Evolution 60:922-933.

Pagel, M. 1997. Inferring evolutionary processes from phylogenies. Zool. Scr. 26:331-348.

. 1999. Inferring the historical patterns of biological evolution. Nature 401:877-884.

Paradis, E., J. Claude, and K. Strimmer. 2004. APE: analyses of phylogenetics and evolution in R language. Bioinformatics 20:289-290.

Payne, J. B. 1980. Synecology of Malayan tree squirrels with special reference to the genus Ratufa. Ph.D. thesis, University of Cambridge, Cambridge, U.K.

Piaggio, A. J., and G. S. Spicer. 2000. Molecular phylogeny of the chipmunk genus Tamias based on the mitochondrial cytochrome oxidase subunit II gene. J. Mamm. Evol. 7:147-166.

Pinheiro, J., D. Bates, S. DebRoy, D. Sarkar, and R. C. Team. 2014. nlme: linear and nonlinear mixed effects models. R package version 3.1-117.

Plummer, M., N. Best, K. Cowles, and K. Vines. 2006. CODA: convergence diagnosis and output analysis for MCMC. R News 6:7-11.

R Core Team. 2014. R: a language and environment for statistical computing. R Foundation for Statistical Computing, Vienna, Austria.

Rabosky, D. L. 2012. Positive correlation between diversification rates and phenotypic evolvability can mimic punctuated equilibrium on molecular phylogenies. Evolution 66:2622-2627.

2014. Automatic detection of key innovations, rate shifts, and diversity-dependence on phylogenetic trees. PLoS One 9:e89543.

Rabosky, D. L., and D. C. Adams. 2012. Rates of morphological evolution are correlated with species richness in salamanders. Evolution 66:18071818.

Rabosky, D. L., G. J. Slater, and M. E. Alfaro. 2012. Clade age and species richness are decoupled across the eukaryotic tree of life. PloS Biol. 10:e1001381.

Rabosky, D. L., F. Santini, J. Eastman, S. A. Smith, B. Sidlauskas, J. Chang, and M. E. Alfaro. 2013. Rates of speciation and morphological evolution 
are correlated across the largest vertebrate radiation. Nat. Comm. 4:1958. doi: 10.1038/ncomms2958

Rabosky, D. L., M. Grundler, C. Anderson, P. Title, J. J. Shi, J. W. Brown, H. Huang, and J. G. Larson. 2014. BAMMtools: an R package for the analysis of evolutionary dynamics on phylogenetic trees. Methods Ecol. Evol. 5:701-707.

Richards, P. W. 1996. The tropical rain forest and ecological study. 2nd ed. Cambridge Univ. Press, Cambridge, U.K.

Ricklefs, R. E. 2004. Cladogenesis and morphological diversification in passerine birds. Nature 430:338-341.

Rohlf, F. J. 2010. tpsDig, Ecology and Evolution, SUNY at Stony Brook Department of Ecology and Evolution, State University of New York, Stony Brook, NY 11794-524.

Rowe, K. C., K. P. Aplin, P. R. Baverstock, and C. Moritz. 2011. Recent and rapid speciation with limited morphological disparity in the genus Rattus. Syst. Biol. 60:188-203.

Rubidge, E. M., J. L. Patton, and C. Moritz. 2014. Diversification of the alpine chipmunk, Tamias alpinus, an alpine endemic of the Sierra Nevada, California. BMC Evol. Biol. 14:15. doi: 10.1186/1471-2148-1434.

Schluter, D. 1996. Ecological causes of adaptive radiation. Am. Nat. 148:S40S64.

Simpson, G. G. 1953. The major features of evolution. Columbia Univ. Press, New York.

Slater, G. J., S. A. Price, F. Santini, and M. E. Alfaro. 2010. Diversity versus disparity and the radiation of modern cetaceans. Proc. R. Soc. Lond. B 277:3097-3104.

Smith, K. L., L. J. Harmon, L. P. Shoo, and J. Melville. 2011. Evidence of constrained phenotypic evolution in a cryptic species complex of agamid lizards. Evolution 65:976-992.

Steppan, S. J., G. J. Kenagy, C. Zawadzki, R. Robles, E. A. Lyapunova, and R. S. Hoffmann. 2011. Molecular data resolve placement of the Olympic marmot and estimate dates of trans-Beringian interchange. J. Mamm. 92:1028-1037.

Thomas, G. H., and R. P. Freckleton. 2012. MOTMOT: models of trait macroevolution on trees. Methods Ecol. Evol. 3:145-151.
Thorington, R. W., D. Pitassy, and S. A. Jansa. 2002. Phylogenies of flying squirrels (Pteromyinae). J. Mamm. Evol. 9:99-135.

Thorington, R. W., J. L. Koprowski, M. A. Steele, and J. F. Whatton. 2012. Squirrels of the world. Johns Hopkins Univ. Press, Baltimore, MD.

Tran, L. A. P. 2014. The role of ecological opportunity in shaping disparate diversification trajectories in a bicontinental primate radiation. Proc. $\mathrm{R}$. Soc. Lond. B 281:20131979. doi: 10.1098/rspb.2013.1979.

Vrba, E. S. 1987. Ecology in relation to speciation rates: some case histories of Miocene-Recent mammal clades. Evol. Ecol. 1:283-300.

Walker, T. D., and J. W. Valentine. 1984. Equilibrium models of evoluitonary species: diversity and the number of empty niches. Am. Nat. 124:887899.

Wiens, J. J., R. A. Pyron, and D. S. Moen. 2011. Phylogenetic origins of localscale diversity patterns and the causes of Amazonian megadiversity. Ecol. Lett. 14:643-652.

Wilke, T., M. Benke, M. Brandle, C. Albrecht, and J. M. Bichain. 2010. The neglected side of the coin: non-adaptive radiations in spring snails ( $B y-$ thinella spp.). Pp. 551-578 in M. Glaubrecht, ed. Evolution in action: case studies in adaptive radiation, speciation and the origin of biodiversity. Springer-Verlag, Berlin.

Wilson, D. E., and D. A. M. Reeder. 2005. Mammal species of the world: a taxonomic and geographic reference. Johns Hopkins Univ. Press, Baltimore, MD.

Yoder, J. B., E. Clancey, S. Des Roches, J. M. Eastman, L. Gentry, W. Godsoe, T. J. Hagey, D. Jochimsen, B. P. Oswald, J. Robertson, et al. 2010. Ecological opportunity and the origin of adaptive radiations. J. Evol. Biol. 23:1581-1596.

Zelditch, M. L., H. D. Sheets, and W. L. Fink. 2003. The ontogenetic dynamics of disparity. Paleobiology 29:139-156.

Zelditch, M. L., D. L. Swiderski, and H. D. Sheets. 2012. Geometric morphometrics for biologists: a primer. Academic Press, Elsevier (Academic Press), London.

Associate Editor: M. Alfaro Handling Editor: R. Shaw

\section{Supporting Information}

Additional Supporting Information may be found in the online version of this article at the publisher's website:

Figure S1. Phylogenetic relationships of Sciuridae.

Figure S2. Distributions of mean speciation rate, clade age, and species richness.

Figure S3. Phylogenetic optimization of size using maximum likelihood.

Figure S4. First three principal components of shape, with colored polygons (convex hulls) around members of the focal clades.

Figure S5. Correlation between simulated and observed disparity for shape and size. 